\section{artelogie}

\section{Artelogie}

Recherche sur les arts, le patrimoine et la littérature de l'Amérique latine

12 | 2018

Idiosyncrasie de l'indigénisme en Amérique latine.

Pluralité des sources et des appropriations extra-

latino-américaines

\title{
El indianismo en las novelas gráficas latinoamericanas. Los mayas en las historietas de Julio Berríos y de los hermanos Valdes R.
}

\section{Miguel Pimenta-Silva}

\section{OpenEdition \\ Journals}

Edición electrónica

URL: https://journals.openedition.org/artelogie/2259

DOI: 10.4000/artelogie.2259

ISSN: 2115-6395

Editor

Association ESCAL

Referencia electrónica

Miguel Pimenta-Silva, «El indianismo en las novelas gráficas latinoamericanas. Los mayas en las

historietas de Julio Berríos y de los hermanos Valdes R.», Artelogie [En línea], 12 | 2018, Publicado el 07 septiembre 2018, consultado el 21 septiembre 2021. URL: http://journals.openedition.org/artelogie/ 2259 ; DOI: https://doi.org/10.4000/artelogie.2259

Este documento fue generado automáticamente el 21 septiembre 2021

Association ESCAL 


\title{
El indianismo en las novelas gráficas latinoamericanas. Los mayas en las historietas de Julio Berríos y de los hermanos Valdes R.
}

\author{
Miguel Pimenta-Silva
}

Una palabra de aprecio y agradecimiento para con Julio Valdes R. y para con su hijo Alexei por su tiempo, y por su disponibilidad para conversar con el autor del presente estudio, acerca de temáticas múltiples, siempre en torno a la memoria, arte, historia y patrimonio.

\section{Introducción}

1 El artista es un agente de la cultura, pero al mismo tiempo, es un potenciador de cambios intelectuales y políticos. Su papel en la sociedad occidentalizada y capitalista del posguerra va mucho más allá de la producción de obras de artes y performances, su vínculo con la sociedad es umbilical ${ }^{1}$, por eso, su posicionamiento intelectual e ideológico es determinante en su obra, como discurso de la expresión del ser. Los artistas que se dedican al mundo de las novelas gráficas transportan para esos espacios representaciones del presente y del pasado, pero con una ambición de futuro. Dentro del universo de las historietas, América Latina siempre fue un oasis para los artistas ${ }^{2}$ que buscaban innovar pero también criticar a través de sus trazos una sociedad en cambio constante, que viene buscando su lugar en el mundo desde la llegada de Colón a las Américas. El artista latinoamericano tiene la necesidad de considerarse el "otro"; aquel que está al margen; lo que va en contracorriente; él buscador y descubridor de una América original y milenaria.

2 La fusión entre las historietas, un arte de culto - pero marginalizado durante varios años - y la identidad del artista como ser que bebe de la sociedad, pero que necesita de estar al margen de la misma para crear, es fundamental para comprender en profundidad el real valor de los comics. En nuestra opinión los comics deben ser considerados como una fuente de estudio bastante valiosa para temas relacionados con la historia 
contemporánea, en especial en el ámbito de la historia de las mentalidades. El comic como fuente de estudio permite entender como la historiografía académica puede o no influenciar la cultura de masas. Al mismo tiempo ofrece informaciones preciosas relativamente al posicionamientos de los artistas en respecto a determinados temas, siendo capaz de revelar conformidades y resistencias en relación a asuntos específicos. Por otro lado los comics pueden revelar al investigador las fuentes iconográficas y documentales que inspiraron el artista, tornando más claro para el investigador la importancia de los procesos de creación de imaginarios.

3 Dentro de una lectura regional es necesario no olvidar los cambios - por veces violentos que América Latina ha vivido desde del ámbito político e económico en el siglo XX e inicios del siglo XXI. En particular con el inicio de las discusiones antropológicas y filosóficas en torno a los movimientos indígenas y a los conceptos de Indigenismo e Indianismo.

4 Indigenismo e indianismo son dos conceptos distintos, con cargas políticas y filosóficas distintas. Sin embargo cada uno de estos conceptos debe ser contextualizado, según el ámbito de su aplicación. En el campo de los estudios americanistas estos conceptos ganan un valor distinto a otros campos de estudio. En la realidad es muy difícil establecer una visión generalizada en relación a los dos conceptos, ya que cada autor parece tener una visión individual de los conceptos, a pesar de la gran cuantidad de estudios realizados (BARRE, 1983; COMAS, 1953; FRANCH, 1988; GAMIO, 1972; LAUVADE y LESTAGE, 2006; LEYVA SOLANO, 2005; NIEZEN, 2003; SEBRELI, 1991).

5 En nuestra opinión - formada por las lecturas anteriormente mencionadas y por nuestro sentido critico - el indigenismo puede ser entendido como la visión del occidente sobre el indígena americano, tratase pues de una visión desde el exterior, con fines específicos, sobretodo al nivel de una política cultural de inserción del indígena en los Estados. El indianismo es una forma de afirmación del papel del indígena en el mundo (presente y futuro) y en la historia (pasado), donde la política y la filosofía se fusionan. Siendo una forma de legitimación, lucha y resistencia, pero también una forma de vida, que plantea el individuo como un elemento más de la naturaleza.

6 El indigenismo puede también ser comprendido como una forma de colonialismo, ya que su principal objetivo es absorber los indígenas dentro de un sistema occidental. El Indianismo revindica y busca la liberación de los pueblos autóctonos. La diferencia reside entre el acto de oprimir (indigenismo) y el acto de liberar (indianismo).

7 En este estudio procuramos traer a debate el posible posicionamiento a favor de los valores defendidos por los movimientos indigenistas, por parte de algunos autores de historietas del universo latinoamericano, en particular de Julio Berríos (Chile) y Julio Valdes y Erick Valdes (Guatemala).

8 Nuestro objeto de estudio es la forma como es construido el discurso referente al posicionamiento - en relación a los movimientos indigenistas e indianistas - que pueden ser extraídos del universo de las historietas conexos a la civilización maya. Este estudio especifico pretende sobretodo estimular la realización de otros estudios similares relativos a otras culturas prehispánicas.

9 El presente estudio identifica diferencias entre la forma de presentar a la civilización maya en las novelas gráficas de origen latinoamericano y no latinoamericano. Agregase a este objetivo la intención de demostrar la existencia de un ideal relacionado con el movimiento de Indianismo a través de los comics. 
10 Comprender el mundo de las novelas gráficas latinoamericanas, que se han dedicado a los temas mayas, posibilita trazar un perfil teórico de las formas de critica social y legitimación histórica de un espacio ideológico indígena, producido por artistas sensibles a las políticas de indigenismo e indianismo.

11 La utilización de las novelas gráficas como fuente de estudio en trabajos asociados con el mundo de las ciencias sociales no es una novedad ${ }^{3}$, y queda comprobado a cada nuevo estudio, la importancia de la utilización de estas fuentes para la comprensión de los imaginarios occidentales, pero también para entender la forma como algunos discursos ideológicos y de propaganda son distribuidos de forma directa e indirecta a través de los comics. Para el presente estudio el punto de partida son las obras Tolák, El joven guerrero maya (BERRÍOS, 1980); y Kavek (VALDES y VALDES, 2000). Además de estas obras serán mencionadas otras que servirán como base comparativa para sostener y comprobar nuestras hipótesis.

12 Las novelas gráficas serán analizadas en una perspectiva tripartita, teniendo en cuenta la imagen, la narrativa y el contexto. Dentro del análisis de la imagen importa verificar como las representaciones relativas a la civilización maya buscan retratar una realidad histórica o si por el opuesto su intención es la creación de un mundo imaginario con el único propósito de crear un espacio capaz de transportar discursos ideológicos por vía de imágenes. En términos de narrativa, el guión y los diálogos entre personajes son evaluados de forma a comprender el posicionamiento de los héroes como portadores de discurso político-ideológicos. El contexto es uno de los aspectos fundamentales para comprender las verdaderas intenciones del autor y de su obra. El correcto posicionamiento de la obra como una extensión del pensamiento del autor permite identificar una predisposición para la difusión de ideas e ideales.

\section{Dibujando una civilización}

\section{Entre Héroes y Villanos}

13 La presencia del héroe no siempre es requerida en las novelas gráficas latinoamericanas, otras veces es el personaje principal que asume el papel de destaque. Dentro de lo que se puede considerar como figuras heroicas es necesario establecer dos perfiles, el héroe solitario, mucho más asociado con la figura individualista, no representativa de una cultura o de una nación; y el héroe de carácter colectivo representante de los valores del grupo o cultura que representa. Dentro de lo que es la narrativa grafica latinoamericana existe una primacía de los héroes de aspecto colectivo, como modelos de fuerza y valores culturales, transportados y amplificados para un ámbito identitario Indígena.

14 En la obra Tolák, El joven guerrero maya, existe una dualidad de perfiles de héroes que se complementan de forma a destacar mutuamente las característica de ambos, y consecuentemente la civilización que representan. Amito, es un príncipe maya, joven, curioso, a quién no le gusta las reglas establecidas. El astuto y cordial Amito, pertenece a una elite letrada dentro de la cultura maya ${ }^{4}$, pero en parte sus actitudes revelan su desprecio por los encantos de la urbe maya. Es la esencia, la naturaleza quién clama por su atención, y es en ella, que el joven príncipe se siente bien. Pero ese mundo no es el suyo. Es en ese momento que es introducido el otro personaje principal, el cual da su nombre a la obra. Tolák es un joven adolescente, con capacidades físicas capaces de ser equiparadas a su grandeza moral. Tal aspecto queda comprobado cuando el guerrero de 
forma bastante hábil y eficaz termina con la vida de una serpiente que amenaza la vida de Amito. Tolák representa también la cultura maya, en este caso, la cultura no citadina ${ }^{5}$. Véase por las propias palabras del personaje como él comprende su posicionamiento identitario:

«!Parece que efectivamente he salvado a un príncipe! Me pregunto, ¿Qué diría el padre de ese niño, si supiera que su hijo le debe la vida a un auténtico habitante del mayab?» (BERRÍOS, 1980)

15 Tolák además de corajoso es consciente de su posición dentro de su comunidad, siendo presentado como el guerrero más valiente de los suyos. Tal estatuto es concedido no solo por sus capacidades guerreras pero también por su capacidad de interactuar con la naturaleza, con la cual establece un vínculo profundo - sobretodo con su mascota jaguar que funciona como metáfora de su poder, pero también de su respecto para con la naturaleza.

16 En la parte final de la narrativa grafica verificamos como Amito, el joven príncipe a través de su astucia es capaz de libertar a Tolák y su pueblo. Aquí es determinante recordar el perfil de algunos héroes como representativos de los valores de la sociedades a la cual pertenecen. Así Amito es el lado culto, inteligente, astuto de la civilización maya, y Tolák es el lado más guerrero, resistente y valiente de la misma civilización. Son dos mundos que se complementan; dos formas de pensar la civilización maya que confluyen en una misma narrativa.

17 En la misma línea de raciocinio encontramos la novela gráfica Kavek, la cual acompaña la vida de la familia Kavek, teniendo como principal figura - en el primer y único número publicado de serie Kavek - el patriarca Galel. Esta personaje es un guerrero de carácter fuerte y bastante valiente en el campo de batalla, para él, el honor de su familia y de su pueblo es lo más importante. Tal como ocurre con muchos héroes desde del punto de vista de la tradición literaria, también Galel va cambiando al largo de la narrativa, hasta el momento previo a su muerte, cuando abandona la soberbia para darse cuenta que fue cruel y sobretodo manipulado por un gobernante sin escrúpulos. Este hallazgo ocurre por un auto-descubrimiento producido por la interacción entre el personaje y su nahual (figura 1), en este caso un coyote ${ }^{6}$. Galel es miembro de una etnia maya, los $K^{\prime}$ iches, y lucha contra otra etnia maya, los Kaqchikeles. Sin embargo la intención de los autores no es crear un héroe étnico, sino un héroe multiétnico. Esa decisión queda clara en el momento que Galel reconoce que fue manipulado por una elite, y que por eso las otras etnias no eran culpadas, pero si él sistema político-religioso era limitador de una unión entre etnias mayas. Esta concepción de una identidad maya multiétnica es comprobada a través del texto de los autores que acompaña el comic.

18 «Nuestros protagonistas [...] y su descendencia lucharán por el ideal más grande que pueda tener un ser humano, es llevar la gloria a todo su pueblo a través de la reconstrucción del gran imperio maya, el cual está presente en la consciencia de todos sus descendientes en el altiplano y norte del país (actuales departamentos de Huehuetenago, Totonicapán, Quetzaltenango, Sololá, San Marcos, Peten, las Verapaces, y el Quiché) [...] La historia no es patrimonio de unos pocos sino de todo el pueblo que la construye día a día.» (VALDEES y VALDES, 2000).

Cuando hablamos de héroes y de civilización maya, existe una obra que reclama nuestra atención, el Popol Vuh, una narrativa del siglo XVI pero una continuidad del pensamiento prehispánico. Es una lectura obligatoria para quien pretende entender la civilización maya. En este sentido debemos colocar la siguiente cuestión: ¿Es posible identificar en las 
obras de los hermanos Valdes y de Berríos la influencia del Popol Vuh? La respuesta más acertada seria un si, pero no de forma directa. Veamos primeramente la obra de los hermanos Valdes. En ningún momento existe una alusión clara y directa al Popol Vuh, sin embargo para el conocedor de la mencionada obra, existe una ligación muy fuerte entre el comic y el documento histórico. En especial en lo que se refiere a la familia Kavek y a otras personajes y lugares históricos. Sin duda alguna que existe una influencia del Popol Vuh en la obra de los hermanos Valdes. En relación a la obra de Berríos, la ligación con el Popol Vuh es aún más complicada de ser revelada. En nuestra opinión el uso de dos personajes que se complementan entre ellas, de forma a dar un carácter dual al concepto de héroe, expresando así la influencia del Popol Vuh, donde existe la presencia de parejas de héroes. De este modo parece claro que la decisión tomada por Berríos de presentar una pareja de héroes que se complementan, es fuertemente influenciada por el Popol Vuh.

20 Una otra novela grafica que merece atención es Ixtz'unun, nombre que es compartido con la personaje principal, una niña de nueve años que va a vivir diversas aventuras dentro de su propia comunidad. Ixtz'unun es dulce, curiosa y bastante irrequieta como cualquier niña de esa edad. Ella es un vehículo para guiar al lector dentro de la narrativa grafica. Aquí no importan las aventuras del personaje principal, sino la forma como su curiosidad y su relación con los demás personajes va revelando aspectos importantes de la civilización (figura 3), en especial de la civilización maya de tiempos prehispánicos. La joven no es un personaje de carácter singular, más bien representa también ella toda una cultura, siendo la misma novela gráfica una forma de acercar la cultura, sobretodo a un público más joven, utilizando todas las potencialidades de los comics como instrumento de enseñanza en las escuelas y en los medios de comunicación social:

«Hoy Ixtz'unun, una niña maya de nueve años de edad, comienza sus aventuras en la colección que Diario LA PRENSA publica con el patrocinio exclusivo de Banco Ficohsa. Todos los niños y jóvenes de los centros educativos de Honduras y lectores en general están invitados a viajar al templo junto con Ixtz'unun para participar en una ceremonia especial dirigida por el Ajaw, el gobernante de la ciudad donde ella vive. [...] Esta nueva colección es valiosa para introducir a las nuevas generaciones en el conocimiento de una de las culturas más espectaculares de la región mesoamericana: los mayas.» (RODRIGUEZ, 2013)

22 En los tres ejemplos anteriormente presentados se verifica que los héroes son figuras simbólicas de una cultura que no es la cultura occidental, sino de un pueblo originario. El papel de esos héroes, no está asociado a una cuestión de valores morales, su funcionalidad es de orientar al lector dentro de ese mundo prehispánico, un punto de referencia dentro de un universo pensado mayormente para un público americanista. Visiblemente Ixtz 'unun presentase como una intención distinta cuando comparada con Tolák..., y Kavek, ya que su objetivo es claramente llevar el conocimiento de una forma sencilla hasta una parte de la población, en especial, un sector más joven. Así existe una distinción clara, no pudiendo ser posible decir que existe una critica social en la obra. Por otro lado, el hecho de la misma obra estar vinculada a medios de comunicación social y grandes poderes económicos regionales, hace con que la historieta obedezca más a una perspectiva de indigenismo que de indianismo.

23 Las obras Tolák... y Kavek presentan el enemigo como la personalización del poder regente, o sea cuando un determinado personaje asume el rol de villano, o coloca de alguna forma barreras a los héroes, el está poseído de los valores y criticas negativas que el autor entiende como destruidoras de la sociedad. Tal vez por eso parezca existir una 
tendencia a la critica de las reglas y de las elites. Por ejemplo en Tolák... es el gobernante que declara el encarcelamiento y posterior sacrifico del héroe y de sus compañeros, sin embargo, es otro héroe que venido de dentro del sistema - el joven príncipe y representante de ese sistema - quien logra alterar el desfecho de la novela grafica, debido a su insatisfacción y a su rebeldía ${ }^{7}$. Al mismo tiempo es un acto de reconocimiento de la lucha de aquellos que sufren por el sistema regente, pero lo siguen combatiendo a diario. Curiosamente lo mismo pasará en Kavek, cuando en sus últimos momentos el héroe comprende que sus mayores rivales, no son aquellos que hasta entonces luchaban contra él, sino la elite. De este modo quién sufre las consecuencias de los lideres es el pueblo, que sufre con la destruición de las guerras. Así los soldados, tal como los campesinos y resto de la población son iguales entre si a pesar de distinciones étnicas que solamente favorece el crecimiento de las elites político-religiosas. Es la división social como resultado de los discursos políticos y religiosos que produce la muerte, la carencia y la violencia, y es la unión y la tolerancia los únicos caminos para un fortalecimiento de las gentes y en especial de los pueblos originarios.

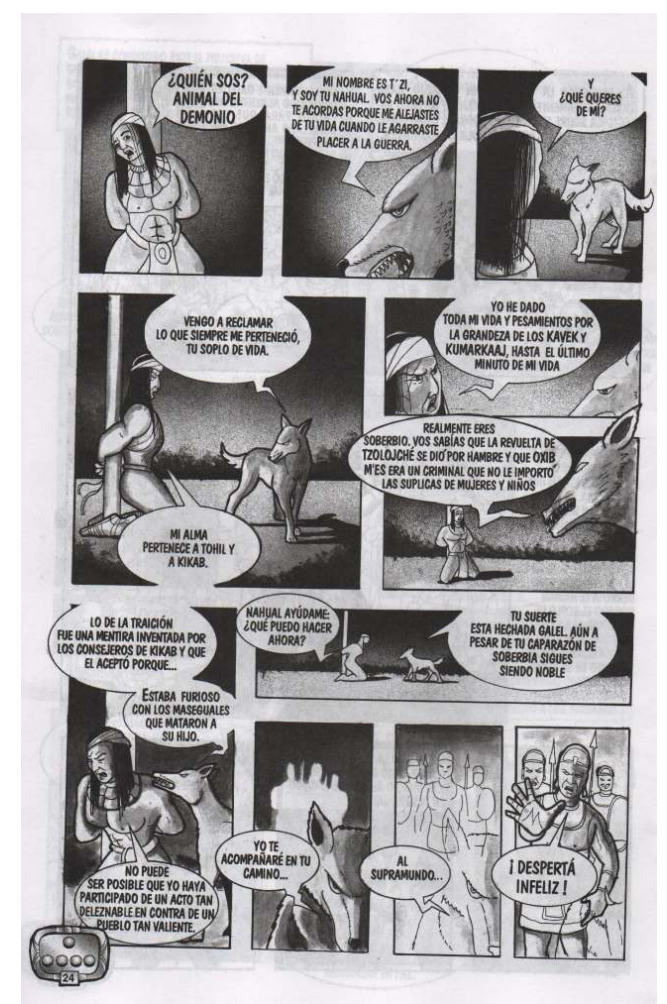

Figura 1 - Kavek, 2000, @Julio Valdes R, y Erick Valdes R. 


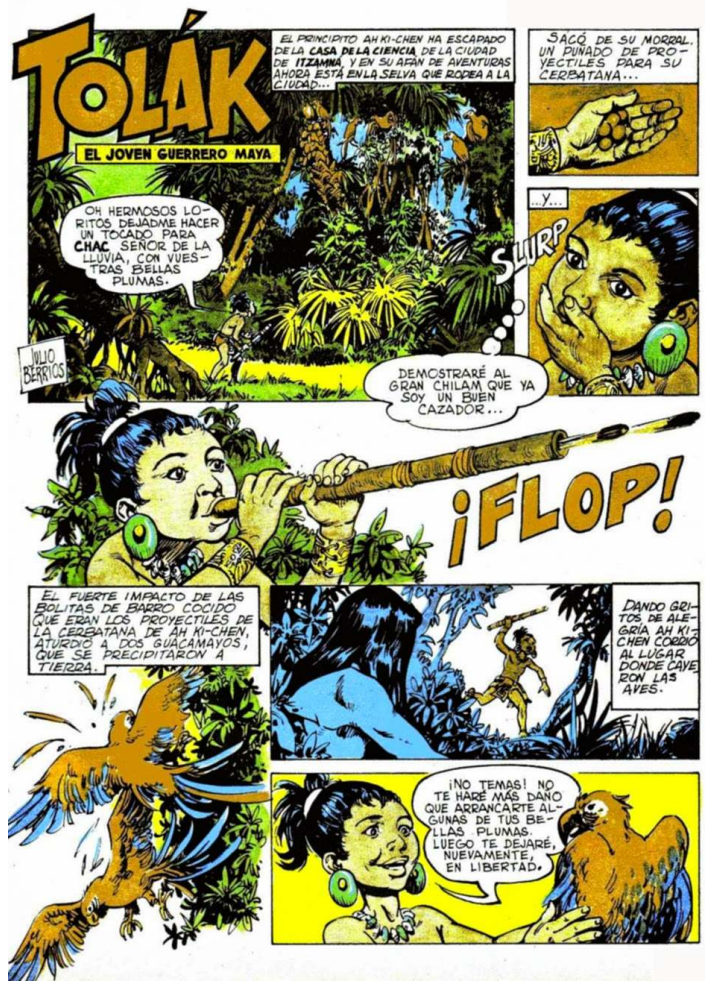

Figura 2 - Tolák, El joven guerrero maya, 1980, C Julio Berríos.
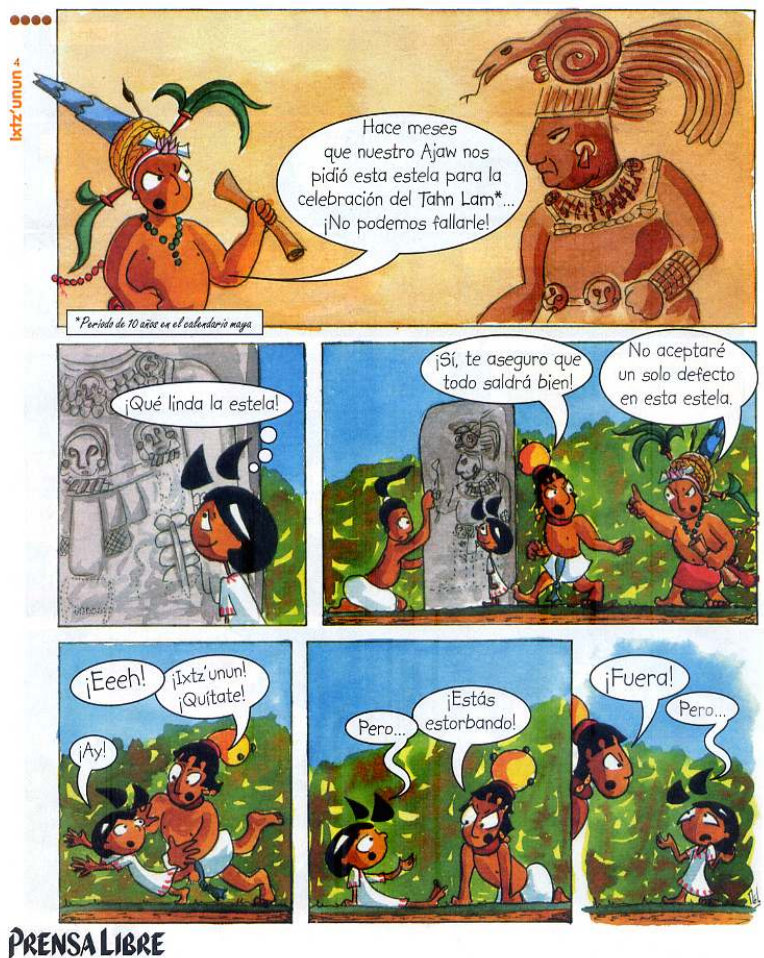

Figura 3 - Ixtźunun: un Nuevo comienzo, 2006, @Mélagie Forné y Edy Barrios. 


\section{Diálogos entre espacios y personajes}

24 La jungla es un escenario constante en las narrativas gráficas relacionadas con los mayas. Hace parte de un imaginario inalterable ${ }^{8}$ de la idea de un convivio sustentable entre hombre y naturaleza. La fauna y la flora son determinantes en los comics para atrapar los lectores en un mundo de misterio. Claro que podía ser posible una aventura pasada totalmente en un entorno urbano, sin embargo al hacerlo el autor limitaría la esencia de la cultura maya en su relación con el natural.

25 Guacamayas y jaguares son frecuentes en el imaginario occidental en relación a la cultura maya, pues de alguna forma, esa es la imagen vendida en la cultura pop, pero también en algunos anuncios publicitaros relativos al turismo. Ese imaginario, es parte del resultado de las investigaciones científicas en torno a los mayas, y sus aspectos artísticos, más específicamente en relación a las iconografías existentes en las cerámicas, monumentos y pinturas murales.

26 Por otro lado, la naturaleza no puede ser entendida solamente como un mero escenario donde ocurre la acción. La naturaleza es un actor secundario, que es colocado en la obra para destacar y apoyar las personajes principales. Ese vinculo queda bien patente tanto en Kavek, con el aparecimiento del coyote como revelador de la verdad, así como en Tolák..., la presencia de la guacamaya sirve para destacar el corazón puro de Amito, ya que el mismo no pretende hacer daño a este animal, buscando solamente sus plumas (figura 2) y dejándole vivo y en libertad. Tratase de una metáfora de la filosofía indianista ${ }^{9}$, donde los pueblos originarios comprenden su lugar en el universo como un elemento más en el mismo y donde existe un relacionamiento balanceado entre civilización y naturaleza.

27 En oposición a la naturaleza está la ciudad, representativa del progreso y al mismo tiempo de las estructuras sociales estratificadas. Las acciones en el mundo urbano son limitadas a interacciones entre los héroes y el poder político-religioso. En el comic de Ixtz 'unun la ciudad aparece representada de una forma distinta, no moralmente reprobable, eso sucede debido al tipo de narrativa grafica que es, sobretodo por su papel de divulgación de la cultura y sociedad maya del periodo prehispánico. Seria casi imposible proceder a una correcta divulgación del conocimiento proveniente de hallazgos arqueológicos ubicados en contexto citadino, sin hacer que la mayor parte de la acción de la novela grafica ocurriera fuera de un universo urbano.

28 Aún dentro del aspecto arquitectónico es importante realzar la importancia de Tikal y su diseño urbanístico como modelo idealizado. Tikal, en la forma de sus estructuras piramidales es lo más representado e inspirador para y por los artistas, pero a través de un análisis detenido es posible verificar que algunas estructuras de Palenque, de la región Puuc y de Chichén Itzá son igualmente fuentes de inspiración para los creadores de historietas e otras formas de arte.

29 Un otro aspecto que debe ser destacado es la influencia proveniente de tiempos prehispánicos además de la arquitectura. En ese aspecto existe una distinción clara entre Tolák... y Kavek. La obra de Berríos no se inspira de forma clara en iconografía existente en artefactos prehispánicos. El único momento visual capaz de generar una duda en relación a este aspecto es la escena de caza donde el joven príncipe carga una cerbatana, recordando en parte alguna iconografía relacionada con la pareja de héroes del Popol Vuh y con una tradición mitológica y artística maya de tiempos anteriores a la conquista. Sin embargo no queda claro se la representación de esta arma está relacionado con una 
influencia iconográfica, o se meramente aparece por motivos particos, ya que la cerbatana es una de las armas más adecuadas para cazar aves. Además la escena narrada en el Popol Vuh presentada en siguiente citación, no está representada en el comic.

«Contaremos ahora el tiro de cerbatana que dispararon los dos muchachos contra Vucub-Caquix, y la destrucción de cada uno de los que se habían ensoberbecido. Vucub-Caquix tenia un gran árbol de nance, cuya la fruta era la comida de VucubCaquix. Éste venía cada dia junto al nance y se subía a la cima del árbol. Hunahpú e Ixbalanqué habían visto que ésa era su comida. Y habiéndose puesto en acecho de Vucub-Caquix al pie del árbol, escondidos entre las hojas, llegó Vucub-Caquix directamente a su comida de nances. En este momento fue herido con un tiro de cerbatana de Hun-Hunahpu, que le dio precisamente en la quijada, y dando gritos se vino derecho a tierra desde lo alto del árbol.» (POPOL VUH, $2008: 35$ ).

En el caso de la obra de los hermanos Valdes es visible la influencia iconográfica de artefactos mayas prehispánicos. Podemos destacar en particular una cerámica maya del Museo Nacional de Arqueología y Etnografia de Guatemala (figura 5), donde un personaje usando unos pantalones de piel de jaguar procede a un baile. La misma acción fue literalmente plasmada en la obra de los hermanos Valdes (figura 4). Revelando el conocimiento del artefacto y la copia de una escena en particular del mismo. De esta forma podemos considerar que existe una opción clara por parte de los artistas de respectar algunos detalles artísticos de la civilización maya.

\section{La otra mirada}

31 Muchos fueron los héroes de la cultura pop que han mantenido contacto con los mayas, estableciendo una posición de disputa o de amistad. Uno de los primeros héroes a tener derecho a una novela grafica totalmente dedicada a sus interacciones fue Tarzan. Tarzan and the castways (KUBERT y BURROUGHS, 1975) es constituida por tres volúmenes: The lost island; Mayan sacrifice; $\mathrm{y}$ Temple of the virgins.

32 La narrativa gráfica empieza con un destaque claro de los valores de Tarzan, en especial su bondad y sentido de justicia, valores que se quedan explícitos con la salvación de un maya, sin embargo y a pesar de su naturaleza étnica, este personaje y su civilización, no se encuentran en lo que serian las tierras mayas, desde una perspectiva histórica y real, pero si en una isla misteriosa en el océano Pacifico.

33 La civilización maya es presentada al largo de la narrativa como una cultura agresiva y bárbara, sobretodo debido a la cuestión de los sacrificios humanos (figura 4), y al despotismo de la elite sacerdotal. Es necesario tener en cuenta que el comic no coloca la civilización maya en el centro de las atenciones, ese lugar es ocupado por la figura de Tarzan. Los mayas son presentados entonces como los grandes rivales del héroe, significando que están asociados a valores que son la antítesis de los valores de Tarzan. De esta forma es posible entender como existe una batalla entre la moral occidental y la moral maya. Entre la idea de buen salvaje y la idea de mal salvaje. Este choque crea en el lector un sentimiento de distanciamiento para con los mayas, ya que en su perspectiva, el lector se identifica con el héroe occidental y tiene desprecio la forma con que los mayas vivían sus practicas religiosas.

34 La civilización maya continua viva, eso significa que hoy cerca de nueve millones de personas son descendiente directos de los constructores de grandes ciudades mayas como Tikal, Copán o Palenque. Y a pesar de un proceso de conquista y evangelización, una 
grande parte de su cultura inmaterial no se perdió, continuando a existir en las tradiciones, costumbres, pero también en los varios idiomas mayas que aún hoy existen. La investigadora Inga Clendinnen (2003) destacó de forma bastante clara que el proceso de conquista y colonización no fue un proceso de una vía única. En parte también los mayas impusieran un modelo de sincretismo especifico, obligando a un dialogo entre colonizadores y colonizados. Desde los primeros tiempos hubo una resistencia bastante activa y solida que supo camuflarse dentro de los sincretismo, o por medio del silencio y de la ejecución alejada de los ojos occidentales, otras veces la resistencia estaba muy visible, como en el caso de la gastronomía (CLENDINNEN, 2003 :159).

Para el pensamiento occidental está relación entre presente y pasado no siempre fue una asociación aceptable, siendo que solamente en la segunda mitad del siglo XIX (PIMENTASILVA, 2013 : 229-233) fue aceptable la idea que los habitantes de las tierras que antes eran mayas, serian también ellos mayas.

36 Este proceso de aceptación fue gradual iniciándose dentro de la academia y trasladándose a la populación general. Ese mismo proceso sigue en funcionamiento hoy en día, una vez que muchas personas aún tienen la concepción errónea que los mayas han desaparecido en el tiempo. Por otro lado, acciones militares que culminaron con el exterminio en masa de muchas comunidades mayas en Guatemala en la década de los años 80 del siglo XX, prueba como los mayas continúan siendo amenazados por un mundo occidental.

37 De alguna forma su pasado y la forma como los primeros conquistadores interactuaran de forma violenta con los mayas, condicionó la forma como el pensamiento occidental creó imaginarios relacionados a los antiguos mayas. En parte ese imaginario parece persistir, hasta en el mundo de los comics de origen no latinoamericana. Por ejemplo Spider-man uno de los héroes más reconocidos de Marvel, también tuvo contacto con los mayas.

38 En The Amazing Spider-Man: The last nameless day (WELLS, 2008) el héroe tiene que enfrentar un conjunto de misteriosos guerreros mayas, que se encuentran en la ciudad durante un rara tempestad de nieve, que cayó sobre la ciudad. Sin duda alguna es uno de los más peculiares guiones existentes en toda la serie de comics de Spider-man. La narrativa presenta un ingeniero informático que al completar un código binario con algunos jeroglifos mayas, hizo con que se produjera un conjunto de amenazas de un grupo de radicales mayas, los cuales tenían su cuerpo tatuado con logogramas mayas relativos al tzolk'in.

En uno de los discursos del programador, él confiesa que recibió muchas amenazas con pasajes del texto del Popol Vuh, en los correos electrónicos se presentaba también una sucinta indicación que refería que era una blasfemia lo que el programador había hecho con los jeroglifos mayas. El personaje prosigue con su narrativa dando indicación que se estaba pasando por el Wayeb, un periodo de ligación entre realidad y los mundos sobrenaturales de los dioses mayas, cuenta aún que contactó con una deidad que buscaba un $K^{\prime}$ uhul Ajaw. Esa misma deidad va a cruzarse con Spider-man y van a tener una fuerte disputa.

Más tarde se verifica que los supuestos extremistas mayas, son en la realidad un grupo que pretendía evitar que se produjesen sacrificios durante el periodo de wayeb, Es de esta forma que el lector comprende que la colocación de los jeroglifos mayas junto con los códigos binarios, no era nada más que una invocación de una deidad maya. 
La historieta se concentra en un imaginario de superstición basado en los calendarios mayas prehispánicos, que siguen en uso en varias partes de Guatemala, Belice y México. La presencia de seres asociados con los antiguos mayas en las aventuras de Spider-man, solo es posible comprender teniendo en atención que Spider-man era uno de los grandes héroes que aún no había tenido contacto, en alguna medida, con la cultura maya, ya que muchos otros héroes de DC Comics y de Marvel han mantenido contacto en alguna medida con esa cultura. Se Trata de una necesidad de juntar el mundo occidental con las grandes civilizaciones de la antigüedad, en muchos casos, establecer una relación de proximidad entre villanos y antiguas culturas, permitiendo realzar el poder del héroe y consecuentemente transmitir una idea subliminal que la civilización occidental es la civilización más poderosa que alguna vez pisó la tierra, al mismo tiempo existe implícitamente una noción de patriotismo norte-americano ya que todos los héroes son provenientes de esa región, creando una metáfora narrativa entre bien y mal, civilización occidental/otras civilizaciones y EE UU como líder de la civilización occidental.

Este posicionamiento de la cultura maya como villana y asociada con el mundo de la superstición y de los sacrificios humanos, condiciona los lectores a que crearen imaginarios parciales de lo que fue y es la civilización maya. El objetivo es bastante claro, glorificar los héroes occidentales modernos en detrimento de una civilización milenaria.

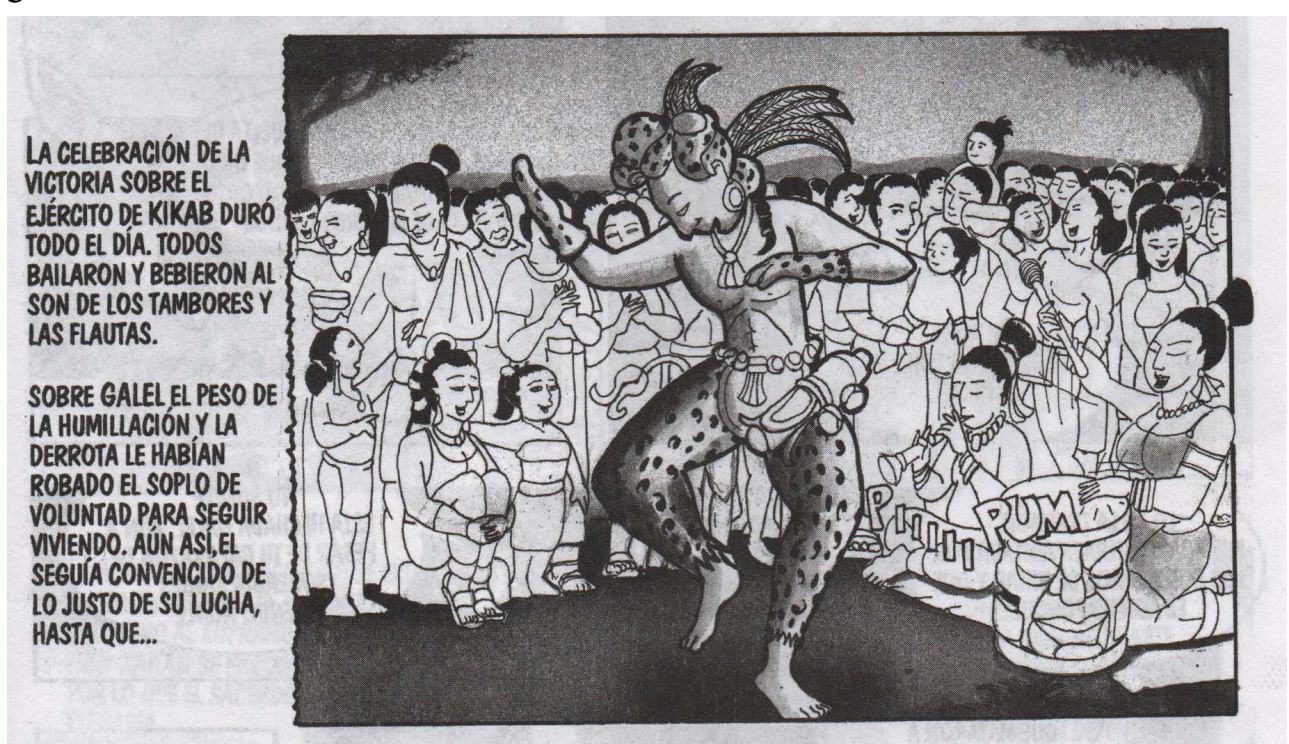

Figura 4 - Kavek, 2000, @Julio Valdes R, y Erick Valdes R. 

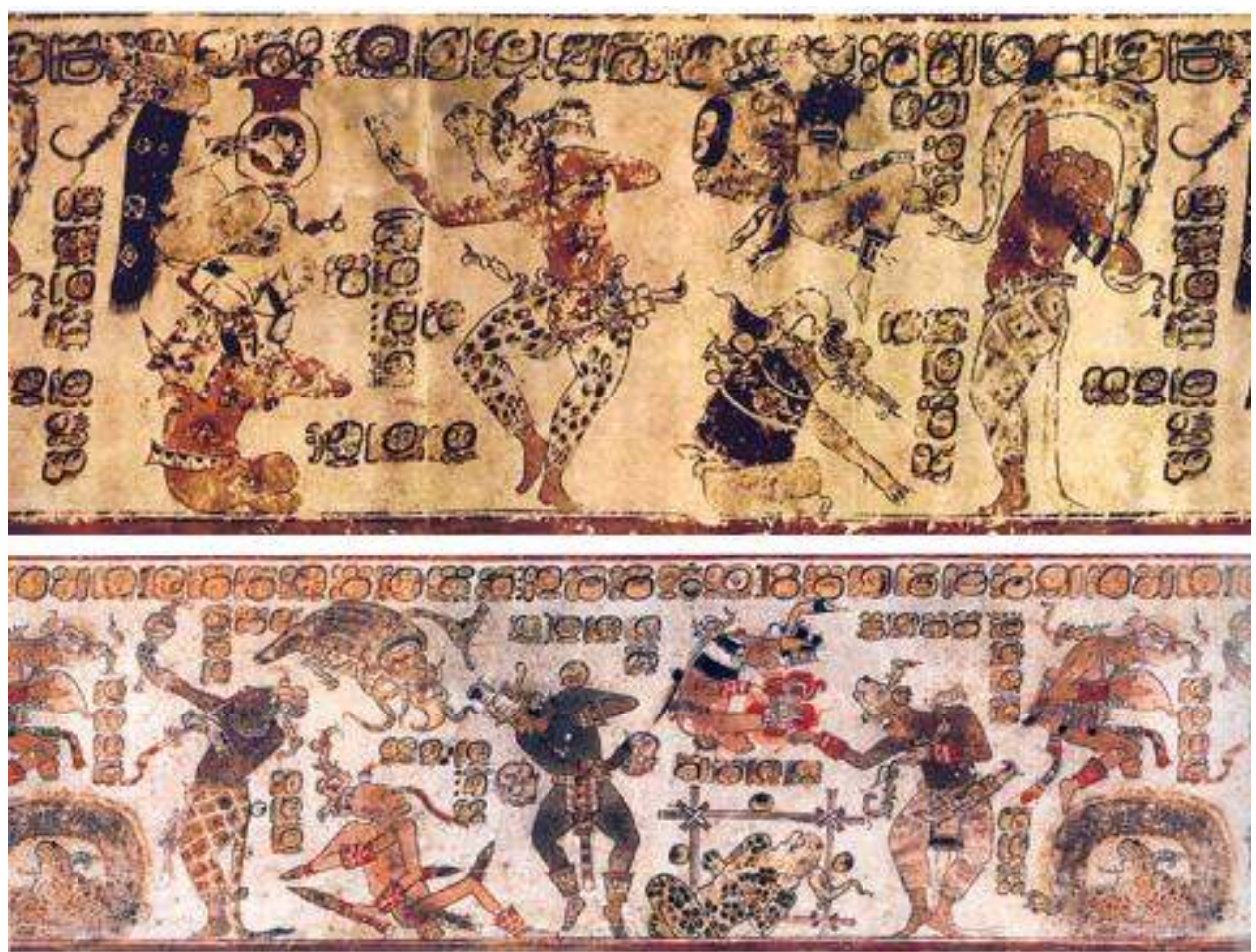

FIgURA 5 - (ARRIBA) VASO DE ALTAR DE SACRIficIOS, MUSEO NACIONAL DE ARQUEOLOgÍA Y ETNOgRAFía de GUATEMALA, GUATEMALA. (K3120) ( JUSTIN KERR. (ABAJO) VASO POSIBLEMENTE DE ALTAR DE SACRIfICIOS, PRINCETON ART MUSEUM, ESTADOS UNIDOS DE AMÉRICA. @ JUSTIN KERR.

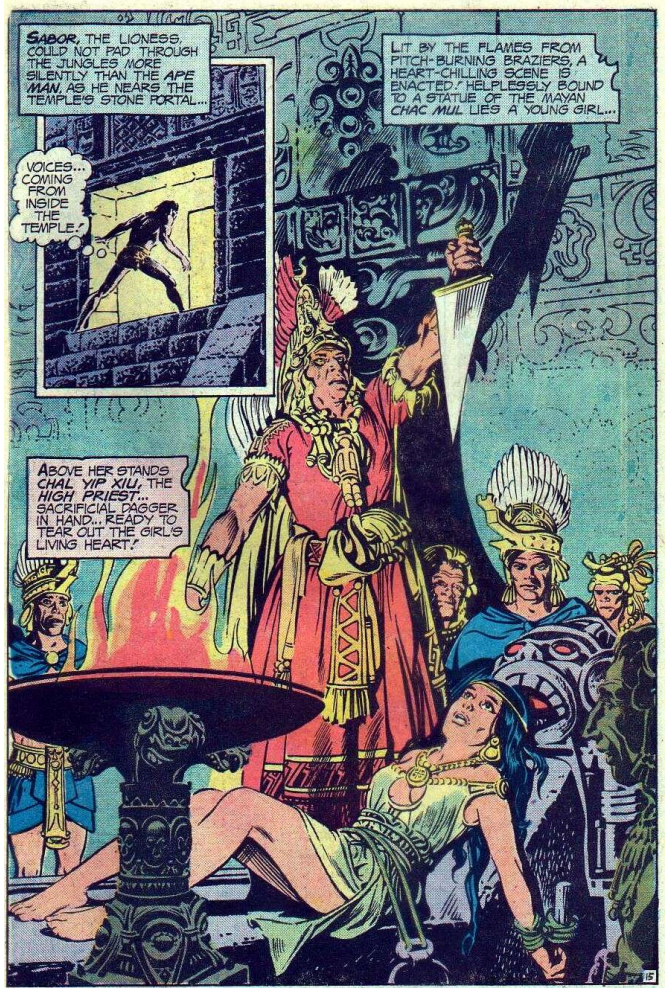

Figura 6 - Tarzan, Mayan sacrifice, 1975, @ Joe Kubert y Edgar Rice Burroughs. 


\section{Consideraciones finales}

43 Las novelas gráficas Tolák,”, y Kavek contienen un mensaje claro de alusión a una necesidad de unión desde de las bases, sin necesidad de una estructura. En parte este discurso es montado sobre una idea del indígena como una esperanza de futuro y de cambio, desde que los mismos sean capaces de abdicar de las estructuras sociales que los atrapan en el presente. Por ese motivo existe una recusa por parte del héroe en vivir en su contexto, forzando una fuga, que es nada más que el inicio de una nueva etapa, el inicio de una perspectiva del indianismo.

Las obras anteriormente mencionadas tienen públicos distintos. Esto ocurre debido a motivos geográficos. En el caso de los hermanos Valdes, además del público general, la obra está direccionada para las varias etnias mayas de Guatemala. Ya en la obra de Berríos, además del público general, la obra tendría como público específico, las comunidades indígenas de Chile, quizá particularmente los Mapuches. Así Berríos utiliza la civilización maya como una metáfora para transmitir un mensaje de apoyo a los movimentos indígenas de Chile en una época en que la nación estaba sobre una ditadura.

45 El impacto que la obras Tolák..., Kavek pueden y pudieran tener es bastante limitado sobretodo debido a los reducidos números de ejemplares producidos, pero también debido al restringido número de lectores. De ese modo muchas de las ideas encriptados en los comics quedan atrapadas en los mismos, mientras el polvo los va consumiendo, sin embargo a cada mano que pasa sobre la portada, a cada soplo que es dado en el intento de quitar el polvo acumulado de los años, existe la esperanza que su contenido pueda formar una persona más tolerante, consciente y creyente en sus capacidades de cambio su entorno, tal como hicieron los héroes de las novelas gráficas.

46 Es notoria la existencia de dos modelos de pensamiento y abordaje distintos cuando comparamos algunos comics latinoamericanos y comics de EE UU. La mayor diferencia es el posicionamiento de la civilización maya en el lado del bien y en el lado del mal, presentando los mayas como héroes o como villanos. Este tipo de opciones obedece a un posicionamiento ideológico por parte del autor, que no solo efectúa este posicionamiento pensando en si mismo pero también pensando en su público. En cierta medida las novelas gráficas de origen latinoamericana, analizadas en este estudio, buscan revindicar un despertar de consciencia; un cambio social; la reunificación del espirito prehispánico, relacionado con su poder y memoria. Para eso, utilizan en particular la figura del guerrero como metáfora de resistencia, resiliencia y fuerza contra todas las adversidades externas. Tales discursos no pueden ser aislados de los movimientos de Indianismo que aparecen en América en la segunda mitad del siglo XX como una respuesta al Indigenismo. El arte es entonces más un elemente de promoción de la defensa y apoyo a esos movimientos dirigidos para el indianismo. 


\section{BIBLIOGRAFÍA}

ANÓNIMO. POPOL VUH: Las antiguas historias del Quiché. Traducción del texto original con introducción y notas de Adrián Recinos. México D. F., Fondo de Cultura Económica, 2008.

BARRE Marie-Chantal, Ideologías indigenistas y movimientos indios, México, Siglo XXI, 1983.

BERRÍOS Julio, Tolák, El joven guerrero maya, Santiago, Mampato, 1980.

CARNERO HOKE Guillermo « Teoría y práctica de la indianidad », en Utopía y revolución. El pensamiento político contemporáneo de los indios en América Latina, compilado por Guillermo BONFIL BATALLA, México, Nueva Imagen, 1981, pp.111-125.

CLENDINNEN Inga. Ambivalent Conquests: Maya and Spaniard in Yucatan, 1517-1570, Cambridge, Cambridge University Press, 2003.

COMAS Juan, Ensayos sobre indigenismo, México, Ediciones de Instituto Indigenista Interamericano,1953.

DOWNEY Elizabeth, « Graphic Novels in Curriculum and Instruction Collections », Reference \& User Services Quarterly, Vol. 49, (nº 2), 2009, pp.181-188.

FIPA, « Federación Indígena Puerto Ayacucho, Territorio Amazonas (Venezuela) », en Indianidad y descolonización en América Latina. Documentos de la Segunda Reunión de Barbados, México, Nueva Imagen, 1979, pp.55-57.

FORNÉ Mélanie y BARRIOS Edy, Ixtz'unun, Ciudad Guatemala, Prensa Libre, 2004-2006.

FRANCH José Alcina «El indigenismo en la actualidad », Gazeta de antropología, (no 6), 1988, http:// www.ugr.es/ pwlac/G06_01Jose_Alcina_Franch.pdf

GAMIO Manuel, Arqueología e indigenismo, México, SepSetentas, 1972.

HENRIQUEZ UREÑA Pedro, Indianidad y descolonización en América Latina, México, Editorial Nueva Imagen, 1979.

GARCÍA Alberto Saladino, «Los valores del indianismo », Raximhai, volumen 9 (nำ2), juliodiciembre 2013, pp.45-68.

GONZÁLEZ Roberto Martínez « La animalidad compartida: el nahualismo a la luz del animism », Revista española de antropología americana, (no 40), 2, 2010, pp.256-263.

KUBERT Joe y BURROUGHS Edgar Rice, Tarzan and the castaways, nํ2 242, DC Comics, Octubre 1975.

LAVAUD Jean-Pierre y LESTAGE Françoise. «El indianismo en la América hispánica. Una nebulosa política equívoca. Política ». Revista de Ciencia Política, (nº 47), 2006, pp.149-169.

LEYVA SOLANO Xochitl. « Indigenismo, indianismo and 'ethnic citizenship' in Chiapas ». The Journal of Peasant Studies, Vol. 32, (nº 3-4), 2005, pp.555-583.

LEYVA SOLANO Xochitl. «Indigenismo, indianismo y 'ciudadanía étnica' de cara a las redes neozapatistas ». Pueblos indígenas, estado y democracia. Buenos Aires, CLACSO, Consejo Latinoamericano de Ciencias Sociales, 2005, pp.279-309. 
MAJO Oscar de « Hugo Pratt: ¿italiano en Argentina o argentino en el mundo? », Signos Universitarios: Revista de la Universidad del Salvador,Vol. 26 (nº 43), 2007, pp.109-124.

NIEZEN Ronald. The Origins of Indigenism: Human Rights and the Politics of Identity. Berkeley, University of California Press, 2003.

PIMENTA-SILVA Miguel « Os antigos maias no pensamento occidental: Entre factos e mitos », Cadmo, (nº 22), 2012, pp. 225-244.

RODRIGUEZ Carlos « Ixtz'unun te enseñará sobre los mayas », Diário La Prensa, (15 de Agosto) 2013, retirado de http://www.laprensa.hn/

SCHWARZ Gretchen « Expanding Literacies through Graphic Novels », The English Journal, Vol. 95, (no 6), Julio 2006, pp. 58-64.

SEBRELL Juan José. « Indigenismo, indianismo, el mito del buen salvaje. ». Cuadernos Hispanoamericanos, (nº 487), Enero 1991, pp.45-68.

VALDES Julio y VALDES Erick, Kavek, nº1, Ciudad de Guatemala, Tohil, 2000.

WELLS Zeb, The Amazing Spider-Man: The last nameless day, colorido por Chris BACHALO y Antonio FABELA, no 556 , Marvel, Junio 2008.

YORK Chris, y YORK Rafiel, « Introduction: Frederic Wertham, Containment, and Comic Books », en Comic books and the cold war, 1946-1962: essays on graphic treatmentof comunism, the code and social concerns, sobre la dirección de Chris YORK y Rafiel YORK, Jefferson, McFarland, 2012, pp.5-18.

\section{NOTAS FINALES}

1. El arte en el posguerra va a tener una importancia vital, en el contexto de la guerra fría y de los usos ideológicos de los discursos artísticos. Tratase de un vehículo de propaganda que fue muy bien manipulado por los estados, de forma directa o a través de un proceso doctrinario sobre los artísticas, haciendo con que los mismos fuesen capaces de producir obras y performances de forma autónoma, pero con un discurso ideológico pleno. Uni de los ejemplos son los comics yankees, durante los años de 1946 y 1962, y la forma como han introducido en sus narrativas varias áreas geográficas, de forma a englobar el máximo posible de culturas, siendo que las culturas africanas y indígenas fueron representadas siempre de forma visiblemente inferior, fuese a través de su ignorancia o de su sumisión (YORK y YORK. 2012 : 6-8).

2. En un tiempo donde los totalitarismos guiaban los destinos de Europa y del mundo para una nueva guerra mundial, los países latinoamericanos y en particular Argentina, eran espacios donde el mundo de la cultura y del arte seguían haciendo parte del cuotidiano, tanto de las elites como de las masas. De todas las artes y formas de literatura, fue la novela grafica quién más se destacó durante los años inmediatamente posteriores a la segunda guerra mundial, alcanzando en ese periodo histórico la época de oro de la historieta en Argentina. En grande medida el artista Hugo Pratt tuvo un papel determinante, trayendo a la historieta en Latinoamérica una nueva forma, solidificando un discurso grafico, ya existente, mucho más adulto, mucho más serio (MAJO, 2007 : 110), y más direccionada a las temáticas históricas. Está escuela argentina de pensar, dibujar y vivir las historietas va a influenciar la realidad artística regional, siendo los países fronterizos contaminados con este nuevo espíritus.

3. En las últimas dos décadas las novelas gráficas cada vez más conquistan su espacio en el esfera mainstream pero también en la academia (DOWNEY, 2009 : 186) sobretodo por la creciente 
comprensión del valor del comic como fuente de estudio de la historia contemporánea, pero también por su capacidad de potencializar el sentido critico en los alumnos (SCHWARZ, 2006: 63) 4. La educación estaba solamente accesible a una parte de la civilización maya en tiempos clásicos. La familia real y algunos grupos sociales como los escribas y sacerdotes podrían tener acceso a la educación (FOSTER, 2002 : 331). Sin embargo la educación no tenia una estructura formal (REAGON, 2008 : 94), así, era organizada mediante las necesidades, aunque existiese conocimientos, tal como los calendarios, que serian siempre abordados dentro de determinados grupos de la elite maya clásica.

5. Existe una critica al mundo de la arqueología y al mundo de la historia, por dar siempre un mayor énfasis a las elites como habitantes de las urbes, en detrimento de la poca atención dedicada a los grupos sociales ligados al campo, en lo que en una lenguaje informal se puede entender como el pueblo. Es Tolák quién da el nombre a la novela grafica, o sea es una historieta enfocada en el pueblo, y no en las elites, sino el nombre de la obra había sido Amito, el joven príncipe maya. La realidad es que existe un gran enfoque en las elites mayas por parte de la arqueología, pero es una situación normal, en la medida que la urbe maya, es capaz de facilitar un mayor número de informaciones que culminan en un mayor número de resultados que asociados nos permiten comprender más en relación a la civilización maya. Así Berríos, él autor de Tólak..., no hace una critica directa a la arqueología como ciencia. Su critica va contra la arqueología como un instrumento del régimen, que busca saber más de las elites, y dejando para un según plan el pueblo. De este modo hace también una critica a la falta de democracia dentro de la memoria histórica y sus esfuerzos para rescatar de forma igualitaria el pasado.

6. Para una mejor comprensión del coyote en la narrativa grafica Kavek sugerimos la lectura atenta de la siguiente citación: «Simultáneamente al nacimiento, una criatura no-humana, llamada nahualli, es en ocasiones asignada a la persona para que la proteja, le asista y aconseje a lo largo de su vida. El hombre y el nahualli comparten una de las entidades anímicas, de suerte que el destino, el carácter y el rol social del primero estarán en relación con la forma del segundo. Consecuencia de ello es también el hecho de que todo daño sufrido por la coesencia tendrá una repercusión directa sobre el sujeto. Aun si ciertos individuos pueden tener varios nanahualtin (plural de nahualli), parece ser que siempre existirá uno que se encuentre más estrechamente ligado a él; las otras coesencias, que por lo general corresponden a especies diferentes, no señalan más que aspectos marginales de la personalidad humana y su muerte sólo provoca enfermedades pasajeras. Dada la variabilidad de los caracteres humanos, hay una gran diversidad de especies-nahualli; aun si éstos son generalmente zoomorfos, también conocemos coesencias vegetales, meteorológicas, minerales, antropomorfas y aun monstruosas - no obstante, su estatus es similar al de un animal.» (GONZÁLEZ, $2010: 256$ ).

7. La rebeldía con que Julio Berríos relaciona la personaje Amito, el príncipe maya, puede ser entendida como una metáfora de un primero paso en el camino de la autoconsciencia de los pueblos originarios, y de la percepción histórica de los discurso anti-indígenas que fueron efectuados al largo de los siglos. «Consecuentemente esa rebeldía innata de los indios los ha llevado a fincar las bases de la recuperación de su propia historia, de la que extraen argumentos para proceder, como por ejemplo recuerdan y señalan: “'Un pueblo que oprime a otro pueblo no puede ser libre', dijo el inca Yupanqui a los españoles. Nosotros, los campesinos quechuas y aymaras, lo mismo que los de otras culturas autóctonas del país, decimos lo mismo. Nos sentimos económicamente explotados y cultural y políticamente oprimidos...”. (CCPCM, 1979: 107). La autoconciencia de los intelectuales indios sobre la génesis de las condiciones de opresión; de la comprensión del despojo de sus medios de producción; acerca de la explotación de su fuerza de trabajo; sobre la destrucción de sus principales manifestaciones culturales y el intento de imponerles - en muchos aspectos se logró - otra cultura, a los pueblos originarios, vino a ser el primer paso para posibilitar la fundamentación teórica de la superación de esa opresiva situación. Los pueblos originarios han acompañado esa autoconciencia con la certeza de que sus 
antepasados prehispánicos no fueron indios, sino la existencia de éstos la explican ya como producto de hechos históricos como la conquista y la colonización; con el combate y rechazo a los estereotipos mediante los cuales se pretende justificar la persistencia de su condición opresiva, de manera que han radiografiado: "La excusa para no solucionar nuestros problemas es repetir lo que desde hace 5 (cinco) siglos inventaron los conquistadores: que somos flojos, ingenuos, viciosos, atrasados y salvajes. Afortunadamente, eso... es falso...” (FIPA, 1979 : 56) » (GARCÍA, 2013 :47).

8. Los imaginarios son persistentes al tiempo, cambiando al final de muchos siglos. Sin embargo, cuando llegar el cambio va siempre permanecer un núcleo duro de los primeros imaginarios. Para el caso maya, es núcleo duro será siempre la jungla. «Para a posterioridade ficarão as mesmas idealizações que possuímos há muitos séculos, a imagem de ruínas de grandes cidades que foram reclamadas pela selva. Construções que desafiam a nossa imaginação e que fazem pensar e questionar como foram edificadas tais cidades. Daqui a alguns séculos será possível responder às muitas interrogações que ainda possuímos. No entanto, a ideia de um mundo perdido perdurará no nosso imaginário enquanto existir a humanidade, pois essa imagem é uma imagem identitária dos Maias, tal como sãp as pirâmides de Guiza para o antigo Egipto.» (PIMENTA-SILVA, 2012 : 239-240).

9. Existe cada vez más una consciencia por parte de los pueblos originarios, en relación a su papel regional y global. Tal consciencia abre puertas a una construcción intelectual de cariz autónomo, culminando - como destaca Alberto Saladino García - en una filosofía Indianista. «Así la nueva concepción acerca de la categoría indio, los pueblos originarios la han trastocado con la sistematización de su propio pensamiento, cuya expresión más alta lo constituye la filosofía indianista. Los rubros de su contenido abarca las más diversas disciplinas filosóficas, pero destacan los de carácter ético con los cuales respaldan su moral, cuyos valores constituyen el cemento aglutinador de la vida de los integrantes de sus comunidades al otorgarle soporte al sentido de su vida misma, dar cuenta de su supervivencia a pesar del embate del mundo occidental y fundar un modo de vida altercapitalista; por ello resulta relevante internarse en la exposición e interpretación del tema de los valores en el marco de su filosofía.» (GARCÍA, 2013 : 46).

\section{RESÚMENES}

El indigenismo es un tema que tiene alimentado mucha producción científica, en especial en el siglo xx. El presente estudio pretende identificar la presencia de discursos indianistas en las historietas de Julio y Erick Valdes R., así como en la obra de Julio Berríos. Para una equidad metodológica de la análisis fueron seleccionadas las historietas Kavek y Tolák, El joven guerrero maya. Ambas dedicadas a la civilización maya. Pretendemos demostrar como las historietas fueron utilizadas por autores distintos en dos puntos geográficos lejanos (Guatemala y Chile), pero con la misma visión y ambición de utilizar las novelas gráficas como vehículo de critica social y de apoyo y legitimación de las culturas indígenas.

L'indigénisme est un sujet qui a alimenté la production scientifique, en particulier au XXe siècle. La présente étude vise à identifier la présence de discours indianistes dans les bandes dessinées des Julio et Erick Valdes R., ainsi que dans le travail de Julio Berríos. Les bandes dessinées Kavek et Tolák, El joven guerrero maya, ont été sélectionnées pour une équité méthodologique de l'analyse. Tous deux dédiés à la civilisation maya. Nous avons l'intention de montrer comment les bandes dessinées ont été utilisées par différents auteurs dans deux lieux géographiques distants (Guatemala et Chile), mais avec la même vision et ambition d'utiliser les bandes dessinées comme véhicule de critique sociale et de soutien et légitimation des cultures indigènes. 
ÍNDICE

Mots-clés: indigénisme, Indianisme, Mayas, Bandes dessinées, Guatemala, Chile

Palabras claves: indigenismo, Indianismo, Mayas, Historietas, Guatemala, Chile

\section{AUTOR}

MIGUEL PIMENTA-SILVA

Universidad Complutense de Madrid

Centro de Historia de Universidade de Lisboa. 